\title{
"CULTURA DE LOS CUIDADOS Y GÉNERO" Y POSTERIOR DEBATE
}

\author{
Dra. Dula F. Pacquiao. \\ (Transcultural Nursing Institute, Kean University, Union, EE.UU.) \\ Jornadas Internacionales de Cultura de los Cuidados. Alicante 14-15 Noviembre 2002.
}

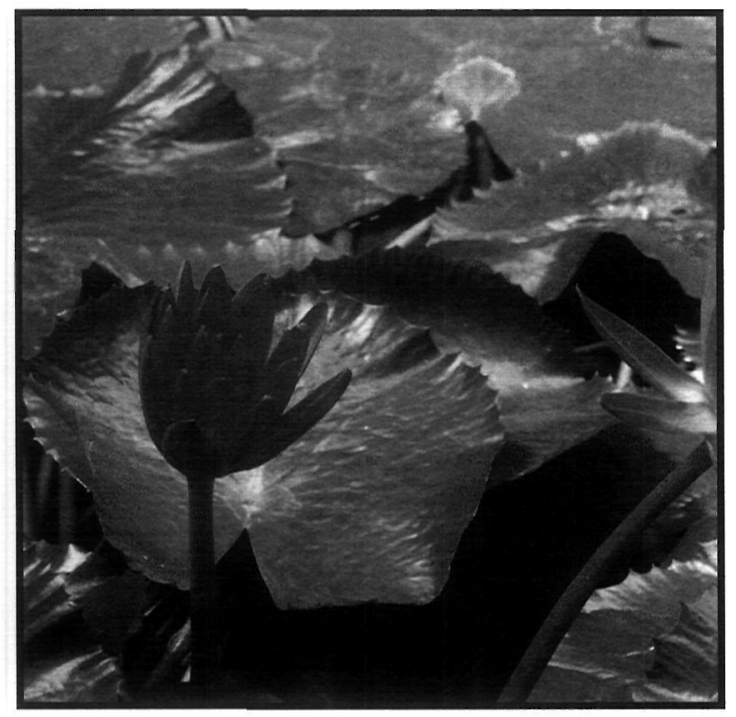

$\square$ stoy encantada de presentarles el modelo que recientemente he desarrollado para afrontar las situaciones de toma de decisiones éticas en competencia cultural. Mi trabajo como consultora del centro Bioético del Medio Oeste en Missouri, Kansas City me ha llevado a crear este modelo que puede resultar útil con los cuidados que se realizan al final de la vida en diferentes culturas.

Mi primer objetivo es diferenciar los cuidados culturales congruentes de los cuidados culturales competentes. El cuidado cultural congruente fue descrito por Leininger como el punto principal del cuidado transcultural. Éste viene acompañado de creencias emic, valores y prácticas de la gente. Debido a que es construido a partir de ellos, el cuidado cultural congruente por lo tanto será significativo, sostenible, habilitador, respetuoso con los valores de la vida e integrador de modelos sobre los valores vitales.

La competencia cultural es la forma de dar cuidados que nos aportan aspectos universales y cul- turalmente específicos del cuidado. La competencia cultural requiere conocimientos, habilidades y actitudes a la hora de dar cuidado cultural congruente a diferentes grupos de gente. Pero no sólo requiere conocimientos culturales sino que también hace referencia a la práctica y el comportamiento de los profesionales de los cuidados.

En la práctica, describimos cuidados culturalmente congruentes y enseñamos a los profesionales a dar una atención cultural pero nos quedamos cortos en esta enseñanza puesto que no se han definido los estándares del conocimiento y el comportamiento propio de la competencia cultural.

Hemos oído en diversas ocasiones que la cultura es el contexto para interpretar nuestras experiencias tales como salud y enfermedad. La cultura también es el mapa cognitivo que nos da las directrices para actuar en estas situaciones.

Las transiciones de la vida son buenos ejemplos de cómo la cultura influye, como pensamos y como actuamos. En muchas culturas no occidentales, el embarazo no está medicalizado, la mujer no acude a un médico puesto que lo considera normal y no como una enfermedad. El parto y el postparto pertenecen puramente a las mujeres en algunas culturas. La figura del hombre no aparece y de hecho algunas son separadas de sus esposos en un cierto período de tiempo después de dar a luz. En algunas culturas la mujer debe pasar por ritos diversos. Roles de edad así como las expectativas de comportamientos apropiados hacia ellos se definen también por la cultural

Una influencia particular de la cultura se puede ver en las premisas morales de la sociedad. Podemos comparar las asunciones morales de occidente con las de culturas no occidentales. Desde el Renacimiento, las culturas occidentales tomaron el concepto de individualidad que les llevaba a la capacidad para razonar y tener un pensamiento lógico. El énfasis de la moralidad es una 
autonomía individual. Cuando la capacidad está en peligro, los profesionales deben proteger legalmente los derechos individuales. En los Estados Unidos, el gobierno indica que los deseos individuales de un paciente deben prevalecer incluso por encima de lo que la familia proponga. Sin embargo, las sociedades no occidentales valoran más la solidaridad y armonía del grupo, ya que se supone que los allegados o familiares siempre actuarán de buena fe y tomarán la decisión más apropiada. De hecho, hay trabajos realizados con grupos de Africanos, Asiáticos e Hispanos en Estados Unidos donde se revelan asunciones morales de grupo familiar.

El concepto cultural dominante de moralidad está encastrado en las organizaciones sanitarias dentro de la sociedad. Es lógico asumir que las organizaciones sanitarias y las culturas profesionales parten de unas bases asumidas que suponen desventajas hacia los grupos más diversos. Esto se ve especialmente cuando diversos grupos son pobres y sin formación. La cultura profesional occidental valora más el reduccionismo, los valores biomédicos y la especialización en contra de las culturas no occidentales que valoran más el no reduccionismo, el holismo y el cuidado natural. Lo natural, supernatural, lo religioso y los aspectos cosmológicos de la vida.

Este modelo reconoce que la competencia cultural es adaptable en varios niveles, no está limitada al profesional únicamente sino también a la organización sanitaria y a la comunidad. He notado que aunque un profesional sea culturalmente competente, éste suele encontrar una fuerte resistencia en la organización y la comunidad.

Este modelo es la síntesis de las ideas de otros autores y tiene tres asunciones principales:

1. - Los seres humanos tienen un derecho a que se tomen decisiones éticas culturales y competentes.

2. - La competencia cultural ocurre en tres niveles: el profesional sanitario, la organización y la comunidad / sociedad.

3. - Se necesitan tres niveles de asistencia cultural: paciente/familia, organizacional y comunitario.

En el continuo de los derechos humanos, el profesional sanitario y la organización deben tener la flexibilidad y adaptabilidad a las necesidades de un paciente occidental quien valora la autonomía individual, la autodeterminación y la parte biomédica así como a las necesidades de un paciente que cree en la figura del grupo o familia, en el holismo $\mathrm{y}$ en las terapias alternativas.

En el nivel organizacional, se pueden examinar los recursos humanos y materiales del cuidado competente cultural tales como la estructura organizacional y las políticas, la relación con la comunidad, los programas de desarrollo, así como los recursos y la disponibilidad de los traductores e intérpretes. La atención prestada a la comunidad se hace prestando atención a los cambios demográficos en la comunidad, a los recursos de diversos grupos y a la capacidad del grupo para reclamar su derecho a un cuidado culturalmente competente. Me encontré con esto en mi último viaje a Leeds en el Reino Unido. Enseñando a la población de Bangladesh lo que debían esperar cuando establecen contacto con el sistema sanitario británico y de que manera combatir el racismo institucional. Las relaciones de colaboración entre la organización sanitaria y la comunidad son parte de la competencia cultural. En New Jersey, un hospital, Englewood Hospital era originariamente de los Testigos de Jehová quienes buscaban tratamientos y cirugía sin sangre pero lo hicieron tan extensible al resto de la población que actualmente acude gente que sin ser testigo de Jehová prefiere la cirugía y los tratamientos que no emplean la sangre.

Los modos de acción de Leininger pueden compararse paralelamente con los niveles que yo planteo. Lo que ahora debemos decidir es que modo de acción corresponde concretamente a cada nivel siempre con el objetivo del cuidado cultural competente hacia el paciente y su familia.

Éste es un ejemplo de cómo el modelo se puede aplicar:

Supongamos que tenemos una paciente (una madre) que es enferma terminal con cáncer quien sabemos que se beneficiará del cuidado del Hospicio. La paciente y su familia son devotos Musulmanes que creen en la predestinación. El hijo mayor de la paciente es el que toma las decisiones desde que su padre murió y no permitirá que el médico hable directamente con su madre para decirle que se está muriendo. De qué manera pode- 
mos preservar la creencia de esta familia de que Dios sólo puede pronosticar una muerte y no los médicos? Qué problemas encontrarían en el Hospicio? Es importante que negociemos con las políticas organizacionales y nos replanteemos la forma en que damos los cuidados para acomodarnos a los deseos de la familia.

Los estudios han mostrado que en Estados Unidos el valor de la autonomía individual como un principio ético se suele colocar por encima de otros principio éticos de beneficencia y no-maleficencia. En el ejemplo anterior, la tendencia es a informar directamente a la mujer de su enfermedad y no hacer caso a las palabras del hijo. Sin embargo, para el hijo, el hecho de que a su madre no le digan que va a morir, resultará mucho más beneficioso para su salud. Por lo tanto, estos principios éticos universales son priorizados diferencialmente en distintas culturas.

$\mathrm{Si}$ aplicamos el modelo en las diferencias de género, aparecen las siguientes ideas:

Los cuidados congruentes de género son preferibles por ciertos grupos culturales tales como los
Musulmanes, los ortodoxos, hindúes... Algunos profesionales tienen dificultades a la hora de trabajar con determinadas jerarquías familiares y éste es un aspecto en que se debe trabajar más.

En España, donde existe un poderoso factor diferenciador entre géneros dentro de las estructuras de las organizaciones sanitarias; se debería hacer más énfasis en la educación y formación de las enfermeras y en general de las mujeres, énfasis en estrategias que valoren la igualdad de género y creen estructuras organizacionales. Si reflexionamos en el trabajo del filósofo brasileño Paulo Freire, el trabajo de la educación es enseñar a los estudiantes a cuestionar y a realizar cambios en las desigualdades que existen dentro de la sociedad.

Espero que les haya gustado que haya compartido algunas ideas con ustedes. Mirar más allá de lo individual dentro del sistema sanitario es importante para que el cambio ocurra.

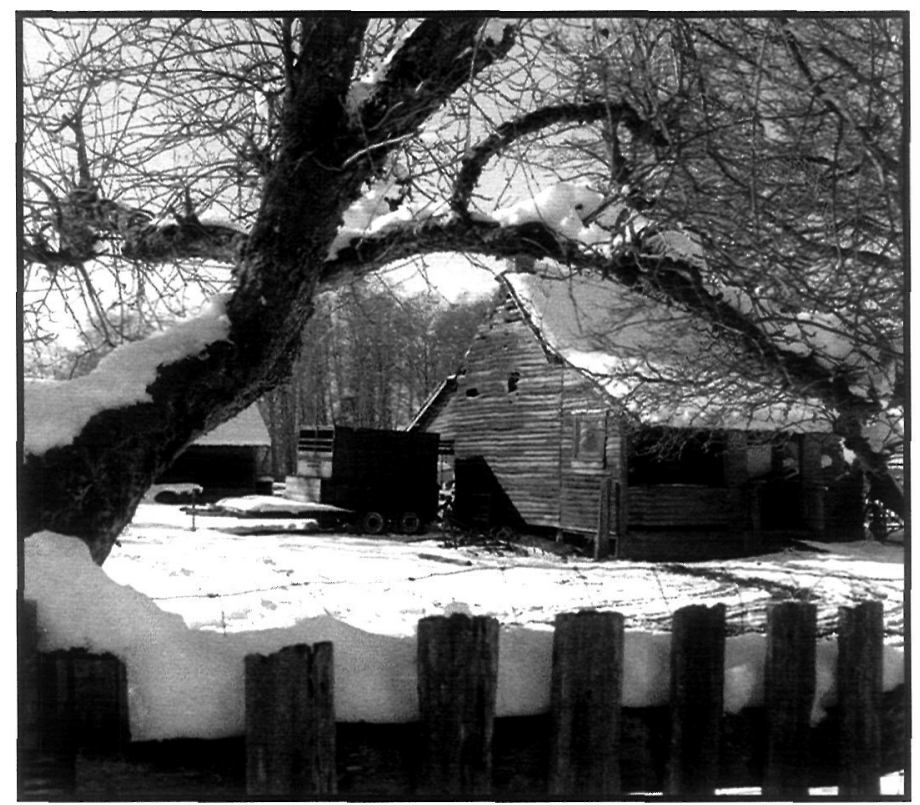

